\title{
Word order in French: the role of animacy
}

\section{Glossa}

a journal of general linguistics

\author{
RESEARCH
}

\section{JULIETTE THUILIER @ \\ MARGARET GRANT \\ BENOÎT CRABBÉ}

\section{ANNE ABEILLÉ (1)}

*Author affiliations can be found in the back matter of this article

\begin{abstract}
A major goal of the quantitative study of syntax has been to identify factors that have predictive power on speaker choices in the face of word-order or valence alternations (e.g. Arnold et al. 2000; Bresnan et al. 2007; Bresnan \& Ford 2010; Bader \& Häussler 2010). In this paper, we study the role of animacy on the order of constituents in French. Animacy has been shown to affect sentence production in other languages, either directly (Feleki \& Branigan 1999; Kempen \& Harbusch 2004; Tanaka et al. 2011) or indirectly through grammatical role assignment (McDonald et al. 1993). Corpus studies however, have failed to find such an effect in French (Thuilier 2012a; Thuilier et al. 2014). Using a sentence recall task, we examined whether animacy has an impact on linear ordering or on grammatical function assignment. While we do find evidence for a role of animacy in the choice between active and passive voice, we do not find a preference to place animate arguments first with ditransitive verbs nor with nominal coordinations. While these findings tend to support the indirect hypothesis (McDonald et al. 1993; Kempen \& Harbusch 2004), we also find what may look like an anti-animacy effect: inanimate direct objects tend to precede animate indirect objects. We propose that canonical mappings between syntactic function and semantic role play a role in putting (inanimate theme) direct objects before (animate recipient) indirect objects, thus overriding the animacy first tendency in French.
\end{abstract}

CORRESPONDING AUTHOR:

\section{Anne Abeillé}

Université de Paris \& LLF, CP 7031 - 5, rue Thomas Mann, 75205, Paris Cedex 13, France anne.abeille@linguist.univparis-diderot.fr

\section{KEYWORDS:}

sentence recall; ditransitive verbs; active and passive voice; coordination; antianimacy effect

\section{TO CITE THIS ARTICLE:}

Thuilier, Juliette, Margaret Grant, Benoît Crabbé and Anne Abeillé. 2021. Word order in French: the role of animacy. Glossa: a journal of general linguistics 6(1): 55. 1-21. DOI: https://doi.org/10.5334/ gjgl.1155 


\section{Introduction}

Given a particular message to be expressed, the language production system is faced with an array of options about the ultimate syntactic form of the associated utterance. Linguists and psycholinguists have long sought to understand what factors condition speaker's choices when there are a number of equally grammatical possibilities. Linguistic factors, such as information structure and constituent length, have been shown to play a role, as have psycholinguistic factors such as recent exposure to a particular structure (structural priming, see e.g., Bock 1986; Ziegler et al. 2019) and the conceptual accessibility of a referent (Bock \& Warren 1985). The role of animacy of a referent can be seen as a psycholinguistic factor (animate referents are thought to be conceptually more accessible, and therefore easier to retrieve during production, see e.g., Branigan et al. 2008) and as a linguistic factor, since animacy is encoded grammatically in many languages. In Section 2, we discuss these two perspectives on the relationship between animacy and word order in more detail. Importantly, one might expect that an effect of animacy due to accessibility might hold across languages, while an effect of animacy due to its encoding in a grammar is expected to vary. In Section 3, we review the factors that have been identified in influencing postverbal complement order in French, and two empirical studies (a corpus study and an experiment) that have failed to find a preference to order animate complements first. The goal of the current study is to reexamine the role of animacy on French constituent ordering from a broader perspective. In Section 4, using a sentence recall task, we examine two cases that have previously been studied for English (Bock \& Warren 1985) and for Japanese (Tanaka et al. 2011) in similar experiments, namely voice alternations for transitive sentences and order alternations in nominal coordination. We add to these two cases ditransitive alternations, which in French allow for free word order of direct and indirect objects without changing other aspects of the structure (unlike dative alternation in English). To preview our results, we find evidence of an animacy effect for voice choice, but not for coordination. Furthermore, we find what may look like an anti-animacy effect for ordering the complements of ditransitive verbs. We discuss these results in light of previous literature and propose an alternative explanation based on canonical mapping between grammatical functions and semantic roles in Section 5, before concluding in Section 6 .

\section{Animacy and word order 2.1 Cross-linguistic overview}

Animacy is an inherent semantic property of referents, which is generally described as spreading across a hierarchy, ranging from the most animate entities (human) to the least animate and least concrete ones (abstract entities). Despite the variety of categories and hierarchies that can be found in the literature (Yamamoto 1999; Zaenen et al. 2004), it is generally acknowledged that the animacy hierarchy can be represented as : human $>$ other animate $>$ concrete $>$ abstract, or as animate $>$ inanimate, in its simplified version. This semantic property is grammaticalized in some languages. For example, the difference between human/animate pronoun he/she and inanimate pronoun (it)) may play a role in syntactic phenomena such as agreement (see e.g. Comrie 2081; Croft 1988) or differential object marking (see e.g. Lazard 1998; Dalrymple \& Nikolaeva 2011).

In some languages, word order is sensitive to animacy. In Sesotho (a Bantu language), the verbal complement ordering depends on the referent's animacy (Morolong \& Hyman 1977). Ditransitive verbs selecting a theme and a benefactive are followed by their complements. When both arguments are human/animate or both non-human/inanimate, they may be freely ordered (1). On the other hand, if the theme is human/animate and the benefactive non-human/ inanimate (or the other way around), the animate argument must precede the inanimate one (2). Thus Sesotho is an example of a language where animacy is a hard grammatical constraint, affecting word order (examples from Morolong and Hyman, 1977: 202-3).

\footnotetext{
a. ke-phehétsé mokété lijó

1SG-cooked feast food

'I cooked food for the feast'

b. ke-phehétsé lijó mokété

1sG-cooked food feast

'I cooked food for the feast'
} 

a. ke-phehétsé ngoaná lijó
1sG-cooked child food
'I cooked food for the child'
b. *ke-phehétsé lijó ngoaná
1sG-cooked food child
'I cooked food for the child'

In other languages, animacy is a soft constraint in the sense of Bresnan et al. (2001). For instance, several studies on the dative alternation in English (Thompson 1990; Gries 2003; Bresnan et al. 2007; Bresnan \& Hay 2008; Bresnan \& Ford 2010) have shown that a referent's animacy partly determines the choice between the prepositional construction (3a) and the double object construction (3b).

a. Kim handed [the toy] [to the baby].

b. Kim handed [the baby] [the toy].

More precisely, corpus data and experimental data (acceptability judgement and sentence completion) show that speakers tend to choose the construction that allows putting the animate referent first: if the recipient is animate (4a), the speaker prefers the double object construction, whereas if it is not, the prepositional construction is favored (4b). Bresnan et al.'s (2007) corpus study showed that an inanimate recipient is over twelve times more likely to be expressed in the preposition structure than an animate recipient.

a. She gave [her mother] [a smile].

b. She gave [a great deal of thought] [to her situation]

Using corpus data, Kempen \& Harbusch (2004) identified a similar effect of referent animacy on German word order. They studied the relative order of pronominal direct object (DO) and non-pronominal subject (S), as well as the relative order of indirect object (IO) and subject. In the first case, complying with the general tendency of putting pronouns before non-pronouns, the DO-S order is much more frequent when the non-pronominal subject is inanimate (85\%). But, the proportion decreases to $51 \%$ when the subject is animate, which reveals a tendency to put animate referents first. As for the ordering between IO and S, they noted that $93 \%$ of the data follow the S-IO order when the IO is inanimate, while the percentage is only $54 \%$ with an animate IO. All these observations comply with animate-first as a soft constraint.

These studies show that the grammar may be sensitive to the animacy of referents, and order animates before inanimates, and that animacy can be implicated in hard, grammatical constraints (Sesotho) or in soft constraints (English, German). In this paper, we focus on the way in which animacy can condition word order in French.

\subsection{Animacy and processing}

In the psycholinguistic literature, it is widely accepted that language processing and sentence production are sensitive to conceptual accessibility, that is "the ease with which the mental representation of some potential referent can be activated in or retrieved from memory" (Bock \& Warren 1985: 50). Assuming incrementality in sentence production (Bock 1982), words that are more easily accessed from memory tend to be produced first (Bock \& Warren 1985). Animate referents have been argued to be conceptually more accessible than inanimates. Thus they tend to be produced first, influencing word order in language production (Branigan et al. 2008).

However, there has been a debate as to the stage of sentence production at which animacy has an effect. One possibility, which Kempen \& Harbusch (2004) call the indirect hypothesis, is that animacy has an effect on word order solely through its influence on grammatical function assignment. For example, animate subjects are preferred, and subjects tend to appear linearly before other arguments, thereby creating a word order effect. The opposing view, the direct hypothesis, proposes that in addition to its impact on grammatical function assignment, animacy also has a direct effect on linear word order.

The results of McDonald et al.'s (1993) experiments on English support the indirect hypothesis. They conducted sentence recall experiments, with active and passive transitive sentences and coordinations of NPs, and noted that animate nouns tend to be used as subjects, either in active or passive sentences, whereas the order of coordinated NPs in a sentence is not affected by 
their relative animacy. They concluded that animacy affects function assignment but not word order if the manipulated nouns share the same grammatical function. In their view, the animate before inanimate effect is only a consequence of grammatical function position in the sentence. ${ }^{1}$ However, English word order is largely determined by the grammatical functions assigned to the phrases, and therefore experiments on English cannot convincingly disentangle the direct and the indirect hypothesis.

Studies examining languages where function assignment and word order are less strongly confounded have supported the direct hypothesis. Feleki \& Branigan (1999) studied Greek SVO and OVS sentences, using the sentence recall experiment paradigm. They observed that whatever the function of the NP is, speakers tended to recall the sentences by putting the animate referent before the verb and the inanimate one after it. Also using a sentence recall task, Tanaka et al. (2011) found evidence for effects of animacy on both function assignment and linear constituent order for Japanese. They tested SOV and OSV orders by manipulating the animacy of the $\mathrm{S}$ and the DO, as well as the voice of the sentence (active vs. passive). Their results showed that animacy affects both the choice of voice and the choice of linear order, but they did not find an animacy effect for conjunct ordering. Thus Japanese data clearly support the direct hypothesis.

In the present study, we examine the effect of animacy on constituent order in French. French has a more fixed word order than Japanese or Greek, but a more flexible one than English. In English, ditransitive verbs combining with a theme and a recipient can be realized either in the prepositional construction (5a) or in the double object construction (6a). In the first construction, the theme precedes the recipient, whereas in the second, the theme follows the recipient. However, the change of ordering is also a change in grammatical function assignment. While in the prepositional construction, the theme is a direct object, as shown by the possibility to promote it as the subject of a passive sentence (5b), in the double object construction, the theme has not the full properties of a direct object, because, notably, it can not be the subject of the passive counterpart of double object construction (6b). In this construction, the direct object is the recipient, which is confirmed by its ability to be promoted as a subject in the passive context (6c); the theme is a second object.

a. The man gives the toy to the baby

b. The toy is given to the baby by the man

a. The man gives the baby the toy

b. *The toy is given the baby by the man

c. The baby is given the toy by the man

In French, only the prepositional construction is possible, and two orders are possible for the same syntactic functions (donner un jouet au bébé/ donner au bébé un jouet). We aim to compare the indirect vs direct hypotheses in our study, shedding further light on the role of animacy in sentence production. We present corpus results, and experimental results (using acceptability judgements and sentence recall). Our results show that animacy plays a role in function assignment, but not in linear order per se. They thus support the indirect hypothesis.

\section{The case of French 3.1 Postverbal complement ordering}

Postverbal complements are rather freely ordered in French. In the case of ditransitive verbs, the indirect object (IO) can either precede or follow the direct object (DO), as shown in example (7).
a. Anne donne [une part de gateau]DO [à son fils]IO
Anne give.3SG a piece of cake to her son
'Anne gives a piece of cake to her son'
b. Anne donne [à son fils]IO [une part de gateau]DO
Anne give.3SG to her son a piece of cake
'Anne gives her son a piece of cake' 
In his 1928 book, Blinkenberg claimed that the French canonical order is DO before IO. This has been confirmed by Thuilier (2012a) on the basis of a corpus of more than 1400 occurrences of ditransitive verbs extracted from four different corpora: the newspaper corpus French Tree Bank (Abeillé et al. 2019), the newspaper corpus Est-Républicain (Seddah et al. 2012), the radio corpus ESTER-2 (Galliano et al. 2006) and the spoken corpus C-ORAL-ROM (Cresti \& Moneglia 2005). The corpus data reveal a strong preference for DO-IO ordering (70.4\%). Moreover, when both constituents have the same length in number of words, this proportion goes up to $77.7 \%$.

Previous studies have shown that this ordering can be probabilistically influenced by several factors: the grammatical weight of each constituent (Blinkenberg 1928; Abeillé \& Godard 2004; 2006; Thuilier 2012a), the semantic class of the verb subcategorizing the complements (Schmitt 1987a; b; Thuilier 2012b; a) and the givenness of the referents (Faghiri \& Thuilier 2018).

To our knowledge, Blinkenberg (1928) is the first to mention the idea that DO and IO are ordered by increasing length in French, for example making (8a) preferred over (8b).
a. Paul dit [à son fils]IO [qu' il fera beau demain]DO
Paul tells to his son that it do.FUT fine tomorrow
'Paul tells his son that the weather will be fine tomorrow'
b. ?Paul dit [qu' il fera beau demain]DO [à son fils]IO.
Paul tells that it do.FuT fine tomorrow to his son
'Paul tells that the weather will be fine tomorrow to his son'

While "heavy" constituents such as complement clauses tend to be second, Abeillé \& Godard (2004; 2006) observe that "light" constituents, such as bare nominals, tend to be first (9).
a. Le clown fait [peur]DO [aux enfants]IO the clown make.3sg fear to.ART.PL child.PL 'The clown frightens the children'
b. *Le clown fait [aux enfants]IO [peur]DO the clown make.3SG to.ART.PL child.PL fear 'The clown frightens the children'
a. Le clown fait [une grande peur]DO [aux enfants]IO the clown make.3sG a big fear to.ART.PL child.PL 'The clown gives a big fear to the children'
b. Le clown fait [aux enfants]IO [une grande peur]DO the clown make.3SG to.ART.PL child.PL a big fear 'The clown gives the children a big fear'

They propose the notion of lightness, which is defined as a new type of syntactic deficiency (Cardinaletti \& Starke 1999), and which is the counterpart of heaviness. Light (or $\mathrm{X}^{\circ}$ ) constituents (Toivonen 2003) display specific syntactic properties: they are not mobile and cannot be extracted. Contrary to heaviness, that tends to put the complement as far as possible from the verb (8), lightness puts it as close as possible to the verb. While bare Nouns are light, noun phrases are not, and are thus more mobile, as shown in examples (10).

Following Wasow's (1997; 2002) corpus study on grammatical weight in English, Thuilier (2012a) observes a clear effect of weight in a corpus of about 1400 sentences. In $82.5 \%$ of the cases, DO and IO are ordered by increasing length. Moreover, Thuilier (2012a) shows that constituent weight should be measured in terms of syntactic complexity but that the number of words is a good estimation of this complexity.

Following the idea by Schmitt (1987a; b), Thuilier (2012b) showed that the semantic verb class also plays a role in complement ordering. In three different corpora (two newspaper and one spoken corpus), she extracted 1434 sentences containing ditransitive verbs directly followed by their two complements, and annotated the semantic verb class according to the semantic classification of the dictionary Les Verbes Français (Dubois \& Dubois-Charlier 1997; Thuilier \& Danlos 2012). She points out that one can get a better modeling of the order of verbal complements when taking into account the verb associated with its semantic class. The most frequent classes were transfer (11), locative (12) and communication (13) verbs with respectively $70.3 \%, 78 \%$ and $57.6 \%$ of DO-IO ordering (Thuilier $2012 \mathrm{~b}$ ). 
[il] avait mis des documents dans un coffre d' une banque [he] have.PST.3SG put.PCPT INDF.PL documents in a safe of a bank à l' étranger

at the foreign

'he had put documents in a safe of a bank abroad'

[...] montrer des armes à ces soldats américains.

[...] to-show INDF.PL weapons to these soldiers americans

'[...] to show weapons to these American soldiers'

In addition to the semantic class of the verb, the information structure of sentences plays a role in their ordering. (Faghiri \& Thuilier 2018) found that postverbal complement ordering is sensitive to the discursive accessibility of the referents, defined as givenness or newness (Prince 1981; Gundel 1988; Arnold et al. 2000). The results of a semi-guided sentence production experiment support the idea that the givenness of the referent affects word ordering as follows: when the referent of the DO is new (not mentioned in the previous context), speakers tend to put it after a given IO (mentioned in the previous context) more frequently than after a new IO. The givenness effect is, however, smaller than the effect of weight.

The above studies show that while postverbal constituent order is relatively free in French, the ordering of any individual IO and DO is probabilistically influenced by at least constituent weight, the semantic class and the discourse status (given vs. new) of the referents involved.

\subsection{On the effect of animacy: previous results}

According to the studies in other languages (English, Greek, German, Japanese a.o.), the animacy constraint can be spelled out as: animate referents tend to appear before inanimate ones. Then, all else being equal, an animate DO should appear before an inanimate IO, as in (14a), and conversely, an animate IO should precede an animate DO (14b).

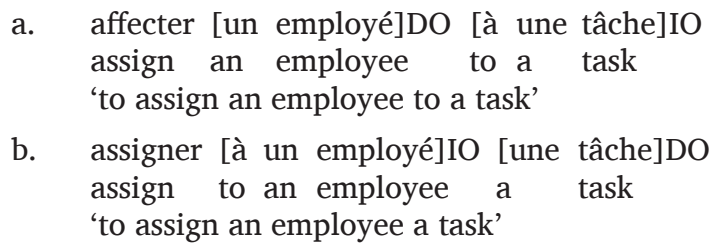

Thuilier (2012a) conducted a corpus study based on the data presented in section 3.1: among the 1434 sentences containing a ditransitive verb followed by a DO and an IO, there were 578 animate IOs and 187 animate DOs. Animate DOs appear in first position in $79.1 \%$ of the cases, and this proportion decreases to $65.1 \%$ when the IO is animate (see Table 1).

\begin{tabular}{llll}
\hline & DO-IO ORDER & IO-DO ORDER & TOTAL \\
\hline animate DO & $148(79.1 \%)$ & $39(20.9 \%)$ & $187(100 \%)$ \\
\hline animate IO & $379(65.6 \%)$ & $199(34.4 \%)$ & $578(100 \%)$ \\
\hline total & $527(68.8 \%)$ & $238(31.2 \%)$ & $765(100 \%)$ \\
\hline
\end{tabular}

At first glance, this indicates a tendency to put animate referents first. However, using multifactorial statistical modelling, which takes into account the effect of several factors simultaneously, Thuilier (2012a) shows that, when the relative length of DO and IO and the semantic class of the verb are included in the model, the effect of animacy disappears. This can be explained by the fact that in the corpus data, animacy is correlated with length and grammatical complexity: animate referents tend to be realized as shorter and less complex constituents than inanimate referents. Hence, the effect of weight seems to override the slight effect of animacy. In other words, the small number of cases where animacy could have an
Table 1 Relative ordering of $\mathrm{DO}$ and $\mathrm{IO}$ according to animacy in Thuilier's (2012) corpus data. 
explanatory power is better explained by a length effect in the corpus data. The corpus data also show a preference for animate IO (75.5\%), which can be explained by the tendency to interpret IO as a recipient or beneficiary.

(Thuilier et al. 2014) report an acceptability judgment experiment aiming to test the effect of animacy on complement ordering in a more controlled way, independently of other potentially correlated factors, such as grammatical weight. 38 participants (students in Paris, native speakers of French) judged the acceptability of 16 items on a Likert scale ranging from 1 to 5 . The 16 items consisted of sentences containing a ditransitive verb followed by its DO and IO (same length in number of words, both definite). They were manipulated for word order (DOIO vs. IO-DO) and animacy of the IO (animate vs. inanimate) varied across items, the DO being systematically inanimate (cf. examples in (15)-(16)).

(15) Il faut que les Israéliens maintenant, dans les prochaines semaines, dans les prochains mois

[DO-IO/-anim] donnent les réponses précises à ces questions.

[IO-DO/-anim] donnent à ces questions les réponses précises.

'It is necessay that the Israelis now, in the next few weeks, in the next few months give the precise answers to these questions'

(16)

Fier de sa pêche, il se promenait sur la rive et

[DO-IO/ + anim] montrait son précieux butin à son copain.

[IO-DO/ + anim] montrait à son copain son précieux butin.

'Proud of his catch, he walked on the bank and showed his precious loot to his friend'

The results show an overall preference for DO-IO ordering, and there was no significant effect of IO animacy nor any interaction of IO animacy with word order. Thus, French speakers do not seem to be sensitive to the animacy of the referents.

Thus far, empirical results fail to support an influence of animacy in determining French complement ordering, either in production (corpus data) or in comprehension/judgement (questionnaire data). Given the importance of animacy cross-linguistically (see Section 2.1) and in language processing more generally (see Section 2.2), this result is somewhat surprising. However, this may be a methodological problem. The results from Greek (Feleki \& Branigan 1999) and Japanese (Tanaka et al. 2011) showed animacy effects on subject-object order during sentence production, rather than ratings as the result of sentence comprehension. To address the question of whether animacy has an influence on word order during the production of French sentences, we designed a sentence recall experiment aiming to test animacy effects in different grammatical constructions.

\section{A sentence recall study}

We report an experiment that investigated whether animacy affects sentence production in French. Since the relative ordering of two constituents may interact with their grammatical function, we selected three sentence types to test whether animacy affects grammatical function assignment, linear order or both: voice alternations (17), the complements of ditransitive verbs (18) and coordination of NPs (19).

Voice Alternation

a. Le policier a trouvé le revolver (Active) the policeman AUX found the revolver 'The policeman found the revolver'

b. Le revolver a été trouvé par le policier (Passive) the revolver AUx been found by the policeman 'The revolver was found by the policeman'

(18) Ditransitive verb

a. Le chef du projet a confié un nouveau budget à un the manager of.the project AUX entrusted a new budget to a décorateur (DO-IO order) decorator 'The project manager entrusted a new budget to a decorator' 
b. Le chef du projet a confié à un décorateur un nouveau the manager of.the project AUX entrusted to a decorator a new budget (IO-DO order)

budget

'The project manager entrusted to a decorator a new budget'

Coordination of NPs

a. Ce jeune homme a toujours fui les traitres et les this young man AUX always avoided the traitors and the échecs (NP1-NP2 order)

failures

'This young man has always avoided traitors and failures'

b. Ce jeune homme a toujours fui les échecs et les this young man AUX always avoided the failures and the traîtres (NP2-NP1 order) traitors 'This young man has always avoided failures and traitors'

With voice alternation, transitive verbs may enter either an active structure (17a), where the agent role matches the Subject function, or a passive structure (17b) with the subject function assigned to the patient, and an oblique function to the agent (par-phrase, akin to an English byphrase). We tested whether the manipulation of patient animacy may affect the choice between active and passive structure in production. If French behaves like other languages (English, Japanese), we expect an animacy effect on voice choice and grammatical function assignment: we expect animate patients to be more likely to be produced as subjects in passive structures (20b), than inanimate patients (17b), all other things being equal. ${ }^{2}$

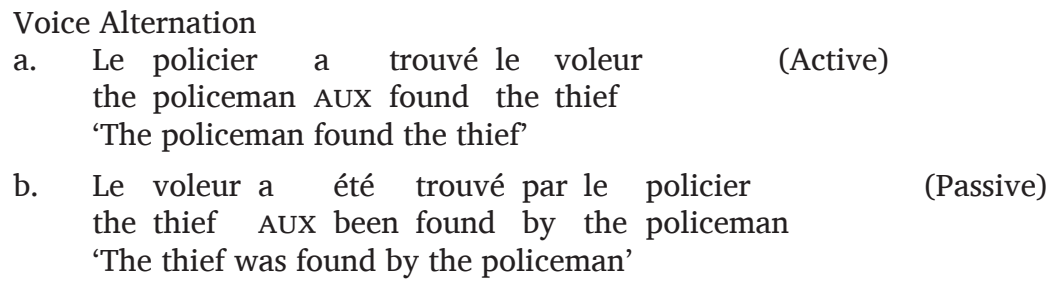

In case of coordination, the NPs are relatively freely ordered in French. One may say either "les avions et les voitures" or "les voitures et les avions" (the planes and the cars, Abeillé et al. 2018). Numerous factors seem to be at play in the choice between both orderings (for English, see Benor \& Levy 2006; McDonald et al. 1993; Fenk-Oczlon 1989; Cooper \& Ross 1975 among others) and one of them might be animacy. In this study, we focus on coordination of an animate with an inanimate NP, as in (19). If animacy affects ordering in French independently of grammatical function, we expect animate NPs to come first (as in (19a)), all other things being equal. If French behaves like other languages (English, Japanese), we expect no animacy effect for coordination.

Finally, our study tests the effect of animacy on the order of complements in ditransitive constructions. As discussed before, two grammatical functions are concerned (DO and IO) here, but there is no possible alternation in grammatical function assignment in French; there is only a word order alternation, as show examples in (18). If animacy affects French ordering directly, we expect that animate DOs are more likely to occur directly after the verb, than inanimate DOs, all other things being equal. If on the other hand, animacy affects French word order indirectly, via grammatical function assignment, we expect no animacy effect since DO-IO is the most common order.

\subsection{Sentence recall}

Following established research in sentence production (see Branigan et al. 2008 for a review), we conducted a sentence recall experiment. The participants task is to recall sentences they have previously read or listened to. Previous evidence (Potter \& Lombardi 1990; Lombardi \& Potter 1992) suggests that sentences in a recall task are reproduced starting at the message level, going through all stages of sentence production, rather than simply being recalled at a

2 In a recent corpus study, da Cunha \& Abeillé (2020) found a significant (first argument) animacy effect for active/passive alternation in French. 
surface level representation. The produced sentences are then compared to the input in order to identify the deviations ("errors") found in participants' productions. Those errors are assumed to reflect underlying biases in the sentence production system, and the analysis of these errors aims to reveal the effect of hypothesized biases.

To test our hypotheses that animacy is involved in grammatical assignation and/or word order in French, we examined the recall of sentences comprising the three structures presented above. In each of the three types, the animacy of one of the NPs varied across the experimental items, while the animacy of the other relevant NP was fixed as "animate", making it possible to examine rates of order/structure inversions as a way to detect effects of animacy on production.

\subsection{Method}

\subsubsection{Participants}

Seventy-seven native speakers of French, between 18 and 30-years-old, participated in the experiment for payment. They were recruited via a French National Centre for Scientific Research (CNRS) mailing list of people volunteering to take part in cognitive experiments (expesciences.risc.cnrs.fr). Participants were split in two experimental groups: Group 1, thirtynine participants, saw the items with voice alternation; and Group 2, thirty-eight participants, was exposed to coordination and ditransitive verbs.

\subsubsection{Items}

We constructed three sets of 24 items each: Voice alternations (Set 1), Coordinations (Set 2) and Ditransitives (Set 3). All experimental items are displayed in Appendix 1. Items of Set 1 started with a prepositional phrase (PP) modifying the critical main clause which contained a transitive verb with two arguments. The verbs belonged to various semantic classes: change of state (bénir 'bless', censurer 'censor', interrompre 'interrupt') and change of location verbs (porter 'carry') with an agentive subject; perception (observer 'observe', regarder 'watch', trouver 'find') and psychological verbs (mépriser 'contempt', ignorer 'ignore') with an experiencer subject. ${ }^{3}$ Each item had four versions such as those in (21), constructed by crossing the animacy of the patient (animate-patient [an-pat] vs. inanimate-patient [in-pat]) with the structure (active vs. passive).
Set 1
[in-pat active] Au bout de la ruelle, le policier a trouvé le revolver
'At the end of the alley, the policeman found the revolver'
[in-pat passive] Au bout de la ruelle, le revolver a été trouvé par le policier 'At the end of the alley, the revolver has been found by the policeman'
[an-pat active] Au bout de la ruelle, le revolver a été trouvé par le policier 'At the end of the alley, the policeman found the thief'
[an-pat passive] Au bout de la ruelle, le voleur a été trouvé par le policier 'At the end of the alley, the thief has been found by the policeman'

In Set 2, items consisted of a verb with its subject and a complement that contained a coordination of NPs (NP1 and NP2), NP1 being set as animate. As with Set 1, we created four versions of each item (22) by crossing the animacy of NP2 (animate NP2 [an-NP2] vs. inanimate NP2 [in-NP2]) and the NPs order (NP1-NP2 vs. NP2-NP1). In order to control the effect of other factors at play in coordinated words ordering, we made sure that the frequency of the coordinated nouns was similar in the subtitle part of Lexique 3 (New 2006) and that the length difference between the two coordinated nouns was not more than one syllable.

\section{Set 2}

[in-NP2 NP1-NP2] Ce jeune homme a toujours fui les traîtres et les échecs 'This young man has always avoided traitors and failures'

[in-NP2 NP2-NP1] Ce jeune homme a toujours fui les échecs et les traîtres 'This young man has always avoided failures and traitors'

[an-NP2 NP1-NP2] Ce jeune homme a toujours fui les traîtres et les lâches 'This young man has always avoided traitors and cowards'

[an-NP2 NP2-NP1] Ce jeune homme a toujours fui les lâches et les traîtres 'This young man has always avoided cowards and traitors'

\footnotetext{
3 Note that Set 1 verbs do not belong to the psychological class favoring passive (with an experiencer object)
} in Ferreira (1994). 
The items of Set 3 are composed of a ditransitive verb combined with an animate subject and an animate PP as indirect object. The four versions of each experimental item (23) were constructed by crossing the animacy of the NP functioning as the verb's direct object (animate DO [an-DO] vs. inanimate DO [in-DO]) with the relative order of the verb complements (DO-IO vs. IO-DO). We controlled for a possible length effect on complement ordering by ensuring that the NP had the same length as the PP, in number of words. To control for information structural effects, the NP and PP were either both definite or both indefinite. We chose verbs from two semantic classes that were the most frequent in our previous corpus studies (Thuilier 2012b): transfer (11) (23) and communication (13). These two verb types can be considered to form a homogeneous class because they both take a dative [à]PP and assign similar semantic roles to their arguments: source-agent, theme, goal-benefactive. Transfer verbs, however, have a stronger preference for DO-IO ordering in Thuilier's corpus study $(70.3 \%)$ than communication verbs $(57.6 \%)$.
Set 3
[in-DO DO-IO] Le chef du projet a confié un nouveau budget à un décorateur 'The project manager entrusted a new budget to a decorator'
[in-DO IO-DO] Le chef du projet a confié à un décorateur un nouveau budget 'The project manager entrusted to a decorator a new budget'
[an-DO DO-IO] Le chef du projet a confié un agent commercial à un décorateur 'The project manager entrusted a business agent to a decorator'
[an-DO IO-DO] Le chef du projet a confié à un décorateur un agent commercial 'The project manager entrusted to a decorator a business agent'

Set 2 and 3 were used for the experiment of Group 2, and Set 1 for the experiment of Group $1 .^{4}$ There were 24 additional items in the Group 1 experiment, which are not relevant for the issues at stake here. In both experiments we added the same 48 fillers. Each participant saw 96 sentences (48 experimental sentences +48 filler sentences) and only one version of each item. The 192 experimental sentences ( 48 items * 4 conditions) of each group were placed in a Latin square design, which means that each version of an item was seen by at least 9 participants, and each participant saw six items in each condition.

\subsubsection{Procedure}

The sentence recall task we used took inspiration from Tanaka et al. (2011), but our method differed somewhat from theirs in that the study phase was visual and the recall phase was spoken, and in the number of sentences per block. ${ }^{5}$ Participants were tested individually in a quiet room. The sentences were presented on a computer screen in 24 blocks, each containing 4 sentences ( 2 experimental items +2 fillers). Each block was composed of 3 phases as shown in Figure 1. During phase 1, participants read the 4 sentences of the block one at a time: each sentence was on the screen for $7 \mathrm{~s}$ and a $600 \mathrm{~ms}$ pause separated each sentence display. Phase 2 was the distractor phase, where participants had to do mental arithmetic. Phase 3 was dedicated to the recall task: participants were prompted for spoken recall using the preambles (e.g. "Au bout de la ruelle..." for (21); "Ce jeune homme..." for (22); "Le chef de projet..." for (23)) in a randomized order different from the presentation phase. Participants were required to respond within $10 \mathrm{~s}$. They completed two blocks of 4 practice sentences before the main experiment. 


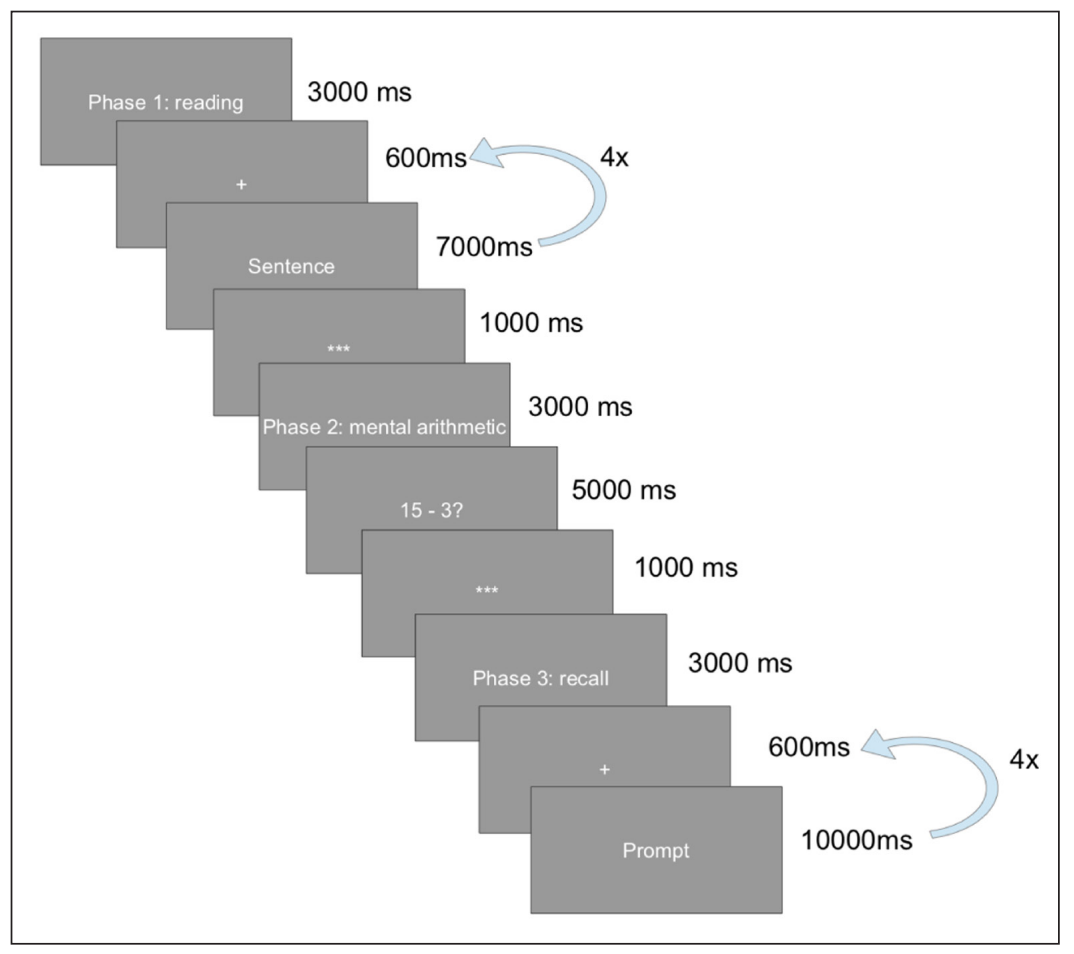

\subsubsection{Scoring}

We transcribed participants' responses and grouped them into three categories: Correct, Inversion, and Other. Responses were scored as Correct when participants recalled correctly the meaning and the structure that had been presented. We accepted synonyms if the animacy was respected. The category Inversion stood for both, word order inversion (Coordination and Ditransitive verb items) and voice inversion (Voice items). Thus, we used the Inversion label when participants correctly recalled the meaning and the animacy of the referent, but used the inverse structure in comparison to the structure that has been presented. All other responses were coded Other. ${ }^{6}$ Participants with less than $30 \%$ of data points in the Correct and Inversion categories together were excluded from the analysis ( 3 participants), as well as subjects and items that had zero observations in a condition. This selection left us with 31 participants and 22 items for Voice alternation; 33 participants and 23 items for Coordination of NPs; and 33 participants and 22 items for Ditransitive verbs. We collected 2200 responses, among which 680 were coded Other $(30,9 \%) .^{7}$

\subsection{Results}

\subsubsection{Voice Alternation}

The frequency of Correct, Inversion and Other responses for each condition are shown in Table 2 and Figure 2. To analyse the results statistically, we used mixed effect logistic regression (Agresti 2007; Gelman \& Hill 2007) to model the binary dependent variable "Recalled response" (Correct vs. Inversion; Other responses were left out the statistical analysis). This model predicts the probability of having an Inversion given the fixed and random effects. Our models were implemented using the lme4 package (Bates et al. 2015) in R ( $\mathrm{R}$ Development Core Team 2011). In the model, the fixed effect was Animacy and the random effects were intercepts for Subject and Item. There were only two inversions from active to passive, with zero inversions from active to passive in the Inanimate condition. This was not unexpected, given that sentence recall experiments tend to elicit errors toward the more natural variant in an alternation, in this case the active form, rather than toward the more marked form, in this case the passive. 
These small values eliminate the possibility of conducting our planned statistical analysis, logistic mixed-effects regression. To avoid the issue of zero and near-zero observations in two cells, we conducted our analysis on the passive-active inversions only. We observe that there were many more inversions in the Inanimate condition. In other words, participants tended to recall passive sentences with inanimate patient as active sentences (see examples in (21)), by putting the inanimate patient in direct object position. This observation is confirmed by statistical analysis. The model is summarized in Table 8 (Appendix 2). The results of the Voice Alternation experiment showed that participants changed the structure of the sentence only when the input was passive. Moreover, the passive to active inversions are significantly affected by the animacy of the patient: an inanimate patient favors Inversion from passive to active, like in English and Japanese.

\begin{tabular}{|c|c|c|c|c|}
\hline \multirow[t]{2}{*}{ PATIENT ANIMACY } & \multirow{2}{*}{$\begin{array}{l}\text { INPUT WORD } \\
\text { ORDER }\end{array}$} & \multicolumn{3}{|c|}{ RECALLED RESPONSES } \\
\hline & & CORRECT & INVERSION & OTHER \\
\hline \multirow[t]{2}{*}{ Animate } & Active & 110 & 2 & 56 \\
\hline & Passive & 101 & 13 & 62 \\
\hline \multirow[t]{2}{*}{ Inanimate } & Active & 124 & 0 & 44 \\
\hline & Passive & 66 & 42 & 62 \\
\hline
\end{tabular}

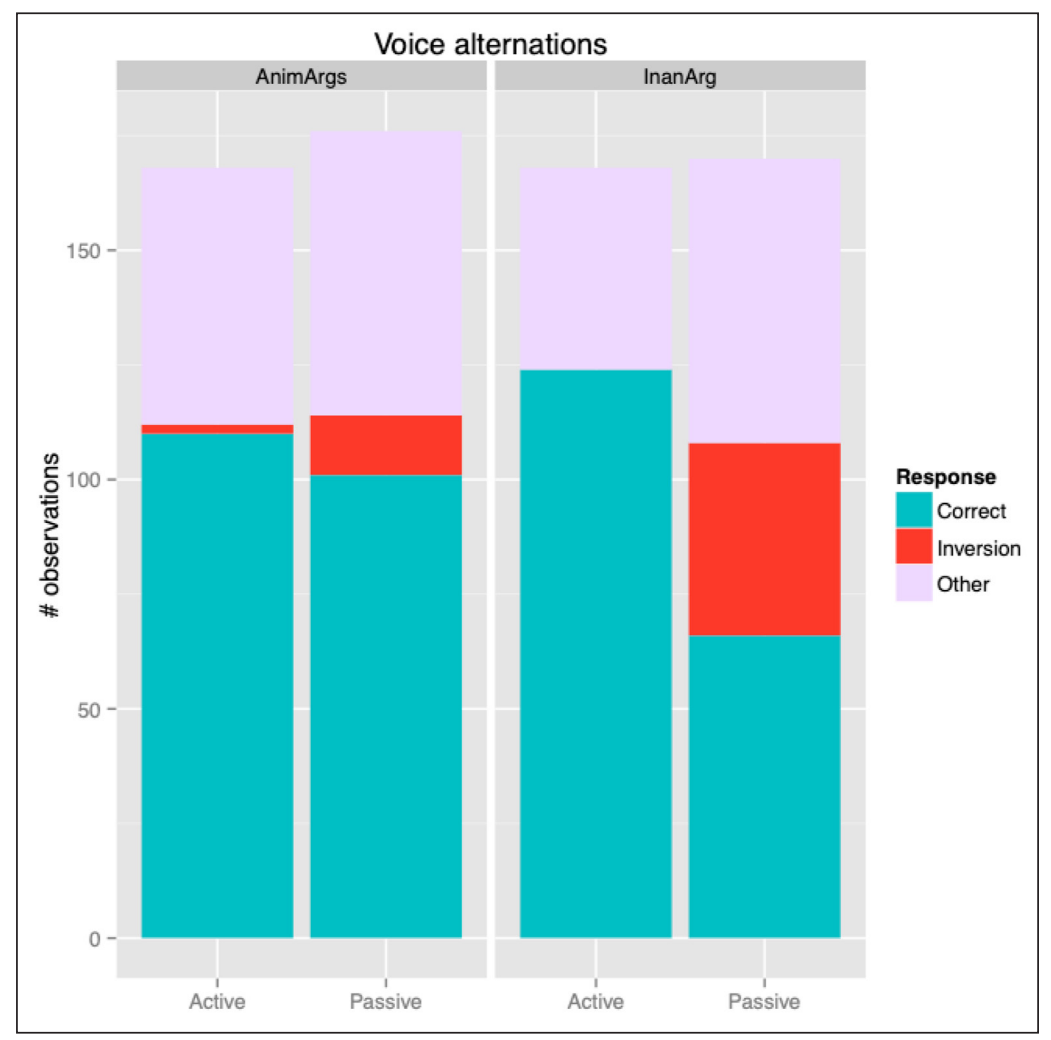

\subsubsection{Coordination of NPs}

The frequency of Correct, Inversion and Other responses for each condition are shown in Table 3 and Figure 3. There are inversions in every condition, but animacy did not show an effect on the distributions of these inversions. We used the same statistical tool as for Voice Alternation, with Recalled response as dependent variable, Subject and Item as random effects. The fixed effects were NP2 animacy, Word order, and the interaction between them. The model is displayed in Table 9 (Appendix 3). None of these factors has a significant effect on the probability of having a word order inversion. Thus, the results indicate a lack of animacy effect on conjunct ordering, like in English and Japanese.
Table 2 Results of the recall experiment (voice alternation).

Figure 2 Results of the recall experiment (voice alternation). AnimArgs: Conditions with both arguments animate; InanArg: Conditions where the theme argument is inanimate. 


\begin{tabular}{lllllll}
\hline \multirow{2}{*}{ NP2 ANIMACY } & INPUT WORD ORDER & & \multicolumn{2}{l}{ RECALLED RESPONSES } \\
\cline { 1 - 1 } Animate & NP1-NP2 & & CORRECT & INVERSION & OTHER \\
\cline { 2 - 3 } & NP2-NP1 & 114 & 22 & 53 \\
\hline Inanimate & NP1-NP2 & 111 & 25 & 54 \\
\cline { 2 - 3 } & NP2-NP1 & 102 & 17 & 70 \\
\hline
\end{tabular}

Table 3 Results of the recall experiment (coordination).

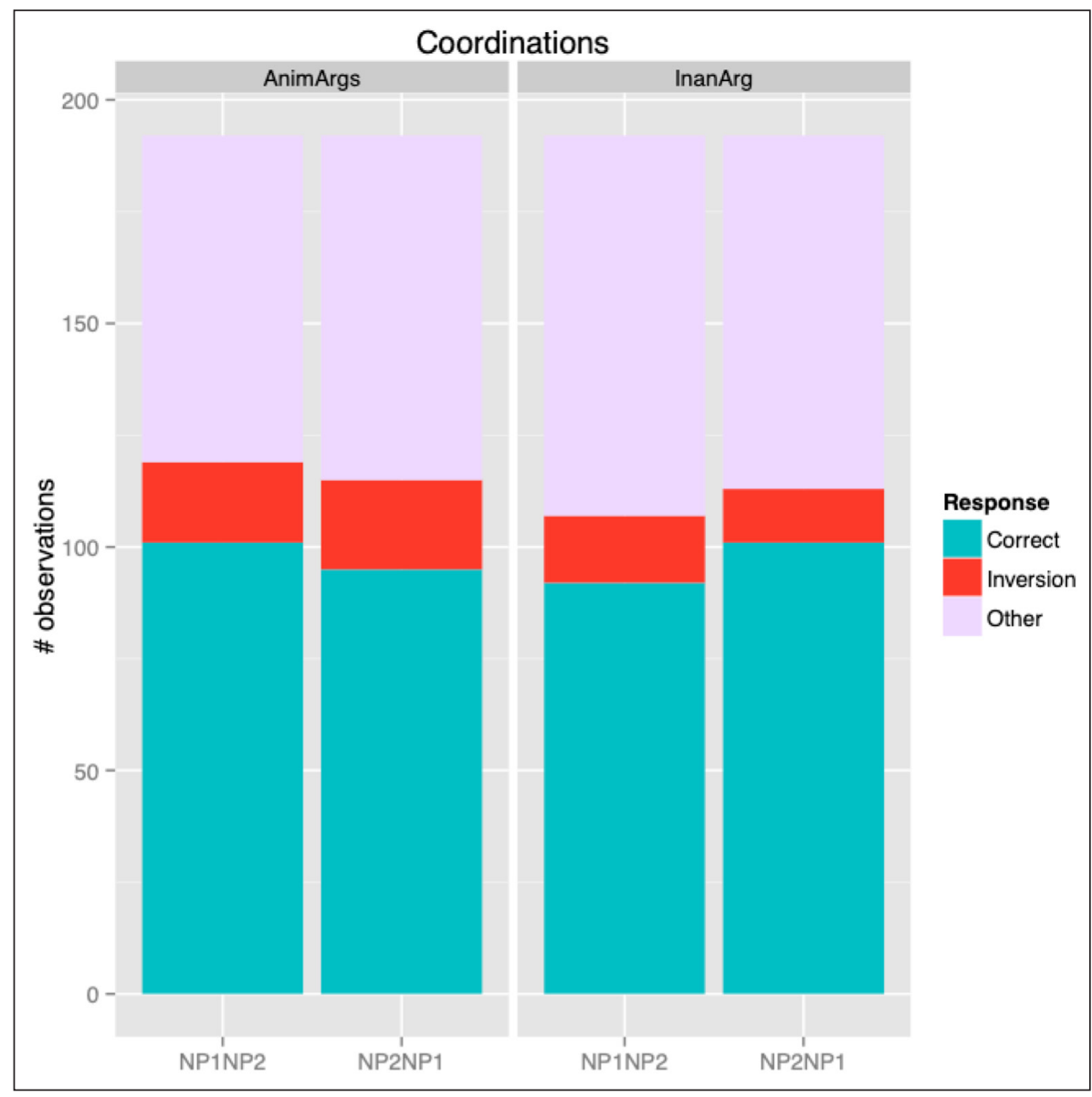

\subsubsection{Ditransitive verbs}

The frequency of Correct, Inversion and Other responses for each condition is shown in Table 4 and Figure 4. There were some inversions in each condition, but we notice that when the DO is inanimate, there were very few inversions from DO-IO to IO-DO (only 6, making $4 \%$ of considered responses), while the number of IO-DO to DO-IO inversions is the highest (28 total, or $21 \%$ of considered responses). In other words, participants tended to produce DO-IO order with inanimate DO, which does not bear out the predicted bias to place animate arguments before inanimates. This observation is confirmed by statistical analysis: a mixed effect logistic regression, with Recalled response as dependent variable, Subject and Item as random effects, and DO animacy, Word Order and the interaction between them as fixed effects. The model is summarized in Table 10 (Appendix 4). The interaction between Animacy and Word Order is significant and can be interpreted as follows: if the stimulus contains an inanimate DO with IO-DO order, the probability of having an inversion increases. Thus, the results show that participants are sensitive to the referent's animacy when ordering postverbal complements, but the interaction seems the reverse of what has been observed for dative alternation in English: French speakers tend to put inanimate complements before animate ones.
Figure 3 Results of the recall experiment (coordination). AnimArgs: Conditions where both conjuncts are animate; InanArg: Conditions where NP2 is inanimate. 


\begin{tabular}{|c|c|c|c|c|}
\hline \multirow[t]{2}{*}{ DO ANIMACY } & \multirow{2}{*}{$\begin{array}{l}\text { INPUT WORD } \\
\text { ORDER }\end{array}$} & \multicolumn{3}{|c|}{ RECALLED RESPONSES } \\
\hline & & CORRECT & INVERSION & OTHER \\
\hline \multirow[t]{2}{*}{ Animate } & DO-IO & 126 & 17 & 48 \\
\hline & IO-DO & 110 & 19 & 60 \\
\hline \multirow[t]{2}{*}{ Inanimate } & DO-IO & 138 & 6 & 47 \\
\hline & IO-DO & 103 & 28 & 57 \\
\hline
\end{tabular}

Table 4 Results of the recall experiment (ditransitive verbs with animate IO).

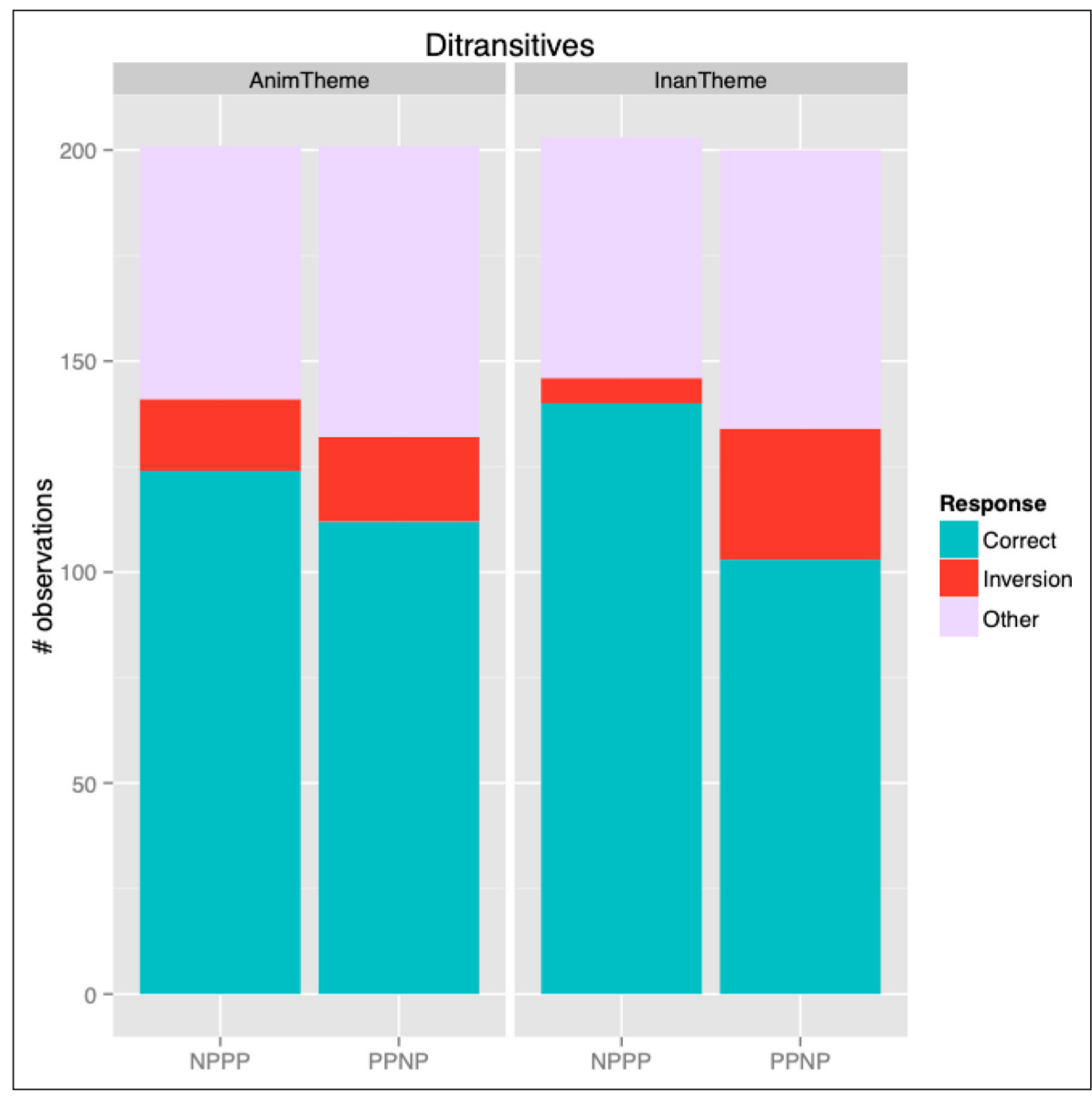

\subsection{Comparison of Filler Items Across Groups}

As mentioned in the procedure, we recruited two groups of participants for our experiment: Group 1 saw items from Set 1 (voice alternations), and Group 2 saw items from Sets 2 (ditransitive alternation) and 3 (coordinations). This design, while essential for maintaining experiment length and avoiding a strong bias toward active sentences in Set 1, limits the conclusions we can draw across item sets seen by different participants. However, in addition to the identical recruitment procedure and random assignment between groups, we argue that rates of correct responses on our filler items, which were the same across Groups, can provide evidence that our groups were equivalent. Table 5 shows the rates of correct and incorrect responses across groups.

\begin{tabular}{lll}
\hline & Group 1 & Group 2 \\
\hline Correct & $1170(76.2 \%)$ & $1344(77.8 \%)$ \\
\hline Incorrect & $366(23.8 \%)$ & $384(22.2 \%)$ \\
\hline
\end{tabular}

Table 5 Rates of correct vs. incorrect responses to filler items by participant group. 
A mixed-effects logistic regression with Group as a fixed effect and random intercept for items showed no significant difference between groups (Estimate $=.100, \mathrm{SE}=0.087, Z=1.151$, $p=.25$ ). The similarity in overall accuracy between groups on the filler items provides some evidence that there was no systematic difference in sentence recall between our groups of participants.

\section{Discussion}

Our experimental results show that voice alternation in French is affected by the animacy of the agent and the patient. This means that conceptual accessibility affects function assignment in French, and confirms what has been observed in other languages (English, Japanese) (Bock et al. 1992; Tanaka et al. 2011). The lack of an animacy effect for coordinations is consistent with previous results in other languages (English and Japanese) (McDonald et al. 1993; Tanaka et al. 2011). Thus the Voice Alternation and the Coordination results comply with what has been found in previous literature and argue in favor of the indirect hypothesis (see Section 2.2): as in English, we observe that conceptual accessibility determines function assignment, but not the relative ordering of phrases sharing the same function.

The results of the ditransitive Verb experiment, on the other hand, seem like an anti-animacy effect: inanimate DOs tend to be produced before animate IOs. Models of processing do not predict this, because they expect an animate before inanimate effect or no effect at all (such as for coordination). At first, our results seem to contradict previous studies on the effect of animacy on verbal arguments ordering (Tanaka et al. 2011; Feleki \& Branigan 1999). However, it is worthwhile to note that we are not dealing with the same kind of verbal arguments as Tanaka et al. (2011) on Japanese or Feleki \& Branigan (1999) on Greek: they studied the relative position of Subject and DO, whereas we are looking at DO and IO ordering. The English dative alternation is more closely related to what we are dealing with, because it involves recipient and theme arguments, but, while the English alternation implies a change in function assignment, the phenomenon we are interested in here only falls under constituent ordering. Thus, rather than contradictory to previous studies, our results are bringing a new piece in the complex puzzle of animacy effect on word order.

In order to give an account of French results that is consistent with the results in other languages, we suggest that animacy effects on word order are constrained by the canonicity of the structures at play. We define canonical structures in terms of grammatical function assignment, linear ordering and prototypical arguments.

- French canonical sentences have an active structure, with an animate argument assuming the Subject function and an inanimate patient being the Direct Object;

- French postverbal canonical ordering is DO-IO, typically with a Direct Object being an inanimate theme; and an Indirect Object being an animate recipient.

The verbs used in our experiments do take prototypical arguments: in Set 1, animate subject (agent or experiencer), and inanimate DO (theme or patient); in Set 3, animate recipient as IO and inanimate theme as DO of transfer and communication verbs. As the status of the DO is crucial for our results and our hypothesis, we checked whether its alleged prototypical inanimacy is verified in ecological data. Corpus data confirm that DO of the verbs used in Set 3 are prototypically inanimate: depending on the verb, between 75 and $100 \%$ of the DOs are inanimate in Thuilier's (2012a) data.

Our hypothesis is that speakers tend to select structures that embody canonical forms, but this tendency can be inhibited by conceptual properties that fail to match the prototypical properties: canonical structure/order is reinforced by prototypical animate or inanimate arguments; and non-canonical structures/orderings tend to be produced by speakers when the arguments have non-prototypical properties -in the case of our experiment, when the patient/theme is animate. With respect to the active-passive voice alternation, the hypothesis generates two predictions:

- As prototypical arguments of transitive verbs, animate agent/experiencer and inanimate patient strengthen canonical active structure, and then favor inversions from passive to active; 
- As non-prototypical arguments, animate patients weaken active structure and reduce the likelihood of triggering passive to active reversals.

The results comply with these predictions: the number of passive to active inversions is proportionally lower when the patient is animate (11.4\%: 13 INVERSION vs. 101 CORRECT), than when it is inanimate (38.9\%: 42 INVERSION vs. 66 CORRECT); and both inversions from active to passive occurred with an animate patient.

As for DO and IO ordering, the hypothesis predicts that:

- As prototypical arguments of ditransitive verbs, animate recipient and inanimate theme strengthen canonical DO-IO ordering, and then favor inversions from IO-DO to DO-IO orders;

- As non-prototypical arguments, animate themes weaken canonical DO-IO ordering and are more likely to trigger DO-IO to IO-DO reversals.

The results comply with these predictions: the number of IO-DO to DO-IO inversions is proportionally lower when the theme is animate (non-prototypical) (14.7\%: 19 INVERSION vs. 110 CORRECT), than when it is inanimate (21.4\%: 28 INVERSION vs. 103 CORRECT); and the proportion of DO-IO to IO-DO inversions is higher with an animate theme $(11.9 \%: 17$ INVERSION vs. 126 CORRECT), than with an inanimate prototypical one (4.2\%: 6 INVERSION vs. 138 CORRECT). The mapping between canonical order (DO-IO) and prototypical arguments (inanimate theme) is sharper for transfer verbs (27.5\% of inversions) than for communication verbs (15.5\% of inversions). In return, the inhibition of the canonical ordering tendency due to non-prototypical arguments (animate theme) is stronger for communication verbs (14.5\% of inversions) than for transfer verbs (9.9\% of inversions). More investigations should be done in order to confirm this pattern.

This hypothesis is also compatible with previous cross-linguistic results, including those of McDonald et al. (1993) on English and Tanaka et al. (2011) on Japanese. As in French, and nominative-accusative languages in general, the active voice is canonical in English and Japanese. Thus, we predict the same tendency as in the current experiment. McDonald et al. (1993) and Tanaka et al.'s (2011) active-passive sentence recall experiments are designed with prototypical arguments (animate agent and inanimate patient) or non-prototypical arguments (inanimate agent and animate patient). In both languages, the passive to active inversions are more frequent with prototypical arguments (25.7\% in Tanaka et al. (2011) Experiment 2 results; $60.9 \%$ in McDonald et al. (1993) results) than with non-prototypical arguments (11.4\% in Japanese; $18.9 \%$ in English). As predicted, the active to passive reversal is more likely to be produced with non-prototypical arguments (32.9\% in Japanese; $12.5 \%$ in English) than with prototypical arguments (9.7\% in Japanese; $1 \%$ in English). The figures are summarized in Table 6.

\begin{tabular}{|c|c|c|c|c|}
\hline & \multicolumn{2}{|c|}{ Passive to Active inversions } & \multicolumn{2}{|c|}{ Active to Passive inversions } \\
\hline & $\begin{array}{l}\text { prototypical } \\
\text { arguments }\end{array}$ & $\begin{array}{l}\text { non-prototypical } \\
\text { arguments }\end{array}$ & $\begin{array}{l}\text { prototypical } \\
\text { arguments }\end{array}$ & $\begin{array}{l}\text { non-prototypical } \\
\text { arguments }\end{array}$ \\
\hline Japanese & $25.7 \%$ & $11.4 \%$ & $9.7 \%$ & $32.9 \%$ \\
\hline INVERSIONS & 96 & 44 & 34 & 119 \\
\hline CORRECT & 278 & 342 & 315 & 243 \\
\hline English & $60.9 \%$ & $18.9 \%$ & $1 \%$ & $12.5 \%$ \\
\hline INVERSIONS & 67 & 7 & 1 & 8 \\
\hline CORRECT & 43 & 30 & 97 & 56 \\
\hline
\end{tabular}

With respect to the verbal arguments ordering, Japanese preverbal ordering is Subject before DO, with an animate Subject as the agent, and an inanimate DO as the patient (that is animate Subject before inanimate DO).
Table 6 Inversions between active and passive structures in Tanaka et al.'s (2011) Experiment 2 and McDonald et al. (1993) results. 
In Tanaka et al. (2011), the proportion of OSV to SOV inversions is higher with prototypical arguments (56.3\% in their Experiment 1 results, with animate agent and inanimate patient) than with non-prototypical ones $(37.4 \%$ in their Experiment 1 results, with inanimate agent and animate patient). There are few SOV to OSV inversions, because there is a clear bias toward the canonical SOV order. However, non-prototypical arguments slightly favor these inversions (5.4\% in their Experiment 1 results, with inanimate agent and animate patient), compared to prototypical arguments (1.8\% in their Experiment 1 results, with animate agent and inanimate patient). Table 7 gives the exact figures. Note that our hypothesis accounts for the animacy effect on word order in Japanese observed by Tanaka et al. (2011): the canonical SOV ordering is strengthened by an animate subject (i.e. prototypical) and inhibited by an animate object (i.e. non-prototypical). Both these facts lead to an animacy first effect: an animate subject favors SOV and an animate object OSV.

\begin{tabular}{|c|c|c|c|c|}
\hline & \multicolumn{2}{|c|}{ OSV to SOV inversions } & \multicolumn{2}{|c|}{ SOV to OSV inversions } \\
\hline & $\begin{array}{l}\text { prototypical } \\
\text { arguments }\end{array}$ & $\begin{array}{l}\text { non-prototypical } \\
\text { arguments }\end{array}$ & $\begin{array}{l}\text { prototypical } \\
\text { arguments }\end{array}$ & $\begin{array}{l}\text { non-prototypical } \\
\text { arguments }\end{array}$ \\
\hline Japanese & $56.3 \%$ & $37.4 \%$ & $1.8 \%$ & $5.4 \%$ \\
\hline INVERSIONS & 81 & 46 & 3 & 8 \\
\hline CORRECT & 63 & 77 & 161 & 147 \\
\hline
\end{tabular}

English postverbal canonical ordering is DO first, and the DO can be either an animate recipient and occur before an inanimate theme as DO2 (double object construction, with animate DO before inanimate DO2), or an inanimate theme preceding an IO not prototypically animate (DO inanimate before IO). Results of corpus studies (Bresnan et al. 2007; Bresnan \& Hay 2008) showed that the canonical double object construction is favored by prototypical animate recipient to a great extent. Moreover, other types of experimental data go in our direction. For instance, in a priming study using dative alternation, Buckle et al. (2017) manipulated the animacy-semantic mappings in order to observe whether animacy affects sentence production apart from structural priming. In their experiment, the animacy-semantic mapping had two possible levels: either an animate recipient and an inanimate theme (transfer of a ball (theme) from a boy to a tiger (recipient)) corresponding to the prototypical mapping, or an inanimate recipient and an animate theme (transfer of a monkey (theme) from a boy to a zoo (recipient)), being the non-prototypical mapping. Their other experimental manipulation was the prime, which was either a double object dative prime or a prepositional dative prime. The participants were asked to describe an animation depicting a scene of transfer, after viewing another animation associated with a dative construction (prime). The results reveal that adult participants tend to produce more double object constructions with animations showing prototypical mappings, whatever the prime condition, and conversely the number of double object constructions is lower when the mapping is non-prototypical, whatever the prime condition. This is in line with our hypothesis: the canonical structure is reinforced by prototypical arguments, and inhibited by non-prototypical arguments. It also shows that the effect is strong, as it is not overridden by syntactic priming.

According to our analysis, animacy effects interact with the mapping between canonical syntactic structure and prototypical arguments. In most of the cases, the canonical structure or ordering makes a prototypical animate argument match the highest grammatical function and/or the first linear position; but, in some cases, as with French postverbal complement ordering, the canonical order puts an inanimate argument first, leading to what we call an anti-animacy effect. Unlike English ditransitive verbs, which have two constructions with two different prototypical mappings (a double object construction with an animate (recipient/ beneficiary) NP1 and a prepositional construction with an inanimate (theme) NP1), French only has one construction with a DO-IO order and a prototypical inanimate (theme) DO. Our proposal suggests taking into account more seriously the semantic roles of the arguments and the semantic verb classes in the study of animacy effect on constituent ordering. It could be tested by gathering experimental data comparing different semantic verb classes and arguments with different semantic roles, and checking whether prototypicality of their arguments affects complement ordering. We leave this for future work. 


\section{Conclusion}

In this paper, we reported the results of a sentence recall study examining the effect of the animacy status of referents on constituent ordering in French, testing three different constructions: active/passive sentences, sentences with coordinated NPs, and ditransitive sentences. Our results support a role for animacy in influencing whether a passive or an active sentence is produced in French, congruent with other studies claiming that animacy has an effect on grammatical function assignment (McDonald et al. 1993; Tanaka et al. 2011). On the other hand, similar to results from other languages, we do not find a bias toward placing an animate entity first with coordinated NPs. With respect to the ordering of postverbal complements in ditransitive sentences, our results show what looks like a French-specific anti-animacy effect. We propose to reformulate the preference for animate argument first as follows: we suggest a more general preference to place prototypical arguments in their canonical positions, which applies to different constructions (active/passive as well as ditransitive) and to different languages (French, English, Japanese) with different results: an animate (recipient) NP1 first in English NP1-NP2 construction, an inanimate (theme) NP1 first in French NP1-PP2 construction.

\section{Abbreviations}

$1 \mathrm{SG}=$ first person singular, 3SG $=$ third person singular, $\mathrm{ART}=$ article, $\mathrm{AUX}=$ auxiliary, $\mathrm{FUT}$ $=$ futur, $\mathrm{INDF}=$ indefinite, $\mathrm{PL}=$ plural, $\mathrm{PST}=$ past, $\mathrm{PCPT}=$ participle, $\mathrm{SG}=$ singular.

\section{Additional files}

The additional files for this article can be found as follows:

- Appendix 1. Stimuli. DOI: https://doi.org/10.5334/gigl.1155.s1

- Appendix 2. Results on voice recall. DOI: https://doi.org/10.5334/gjgl.1155.s2

- Appendix 3. Results on coordination of NPs. DOI: https://doi.org/10.5334/gjgl.1155.s3

- Appendix 4. Results on complement ordering . DOI: https://doi.org/10.5334/gjgl.1155.s4

\section{Acknowledgements}

This work is supported by a public grant overseen by the French National Research Agency (ANR) as part of the program "Investissements d'Avenir" (reference: ANR-10-LABX-0083). It contributes to the IdEx Université de Paris - ANR-18-IDEX-0001. We wish to thank Barbara Hemforth for discussion and comments on the first version of this paper. We also would like to thank the audiences of CLA 2014 (Brock University), IWLP 2014 (University of Geneva), the experimental linguistics seminar 2014 (Université de Paris) and at Quebec University. We received valuable feedback and insightful comments from three anonymous reviewers, whose efforts led to substantial improvements in the text.

\section{Competing interests}

The authors have no competing interests to declare.

\section{Author Affiliations}

Juliette Thuilier (iD) orcid.org/0000-0003-4290-553X

Université Toulouse Jean Jaurès \& CLLE, 5, allées Antonio Machado, 31058, Toulouse Cedex 9, France

\section{Margaret Grant}

Dept of Linguistics, Simon Fraser University, Burnaby, BC V5A 1S6, Canada

\section{Benoît Crabbé}

Université de Paris \& LLF, Université de Paris \& LLF, CP 7031 - 5, rue Thomas Mann, 75205, Paris Cedex 13, France

Anne Abeillé (iD) orcid.org/0000-0002-9187-2298

Université de Paris \& LLF, CP 7031 - 5, rue Thomas Mann, 75205, Paris Cedex 13, France 


\section{References}

Abeillé, Anne, Aixu An \& Aoi Shiraïshi. 2018. L'accord de proximité du déterminant en français. Discours 22. DOI: $h$ ttps://doi.org/10.4000/discours. 9542

Abeillé, Anne \& Danièle Godard. 2004. De la légèreté en syntaxe. Bulletin de la Société de Linguistique de Paris XCIX(1). 69-106. DOI: https://doi.org/10.2143/BSL.99.1.541910

Abeillé, Anne \& Danièle Godard. 2006. La légèreté en français comme déficience de mobilité. Lingvisticae Investigationes 29(1). 11-24. DOI: https://doi.org/10.1075/li.29.1.03abe

Abeillé, Anne, Lionel Clément \& Loïc Liégeois. 2019. Un corpus arboré pour le français: le French Treebank. TAL 60(2).

Agresti, Alan. 2007. An introduction to categorical data analysis. Wiley. DOI: https://doi. org/10.1002/0470114754

Arnold, Jennifer E., Thomas Wasow, Anthony Losongco \& Ryan Ginstrom. 2000. Heaviness vs. newness: The effects of structural complexity and discourse status on constituent ordering. Language 76(1). 28-55. DOI: https://doi.org/10.2307/417392

Bader, Markus \& Jana Häussler. 2010. Word order in German: A corpus study. Lingua 120. 717-762. DOI: https://doi.org/10.1016/j.lingua.2009.05.007

Bates, Douglas, Martin Mächler, Ben Bolker \& Steve Walker. 2015. Fitting linear mixed-effects models using lme4. Journal of Statistical Software, Articles 67(1). 1-48. https://www.jstatsoft.org/v067/i01. DOI: https://doi.org/10.18637/jss.v067.i01

Benor, Sarah B. \& Roger Levy. 2006. The chicken or the egg? a probabilistic analysis of english binomials. Language 82(2). 28-55. DOI: https://doi.org/10.1353/lan.2006.0077

Blinkenberg, Andreas. 1928. L'ordre des mots en français moderne. première partie. Copenhague: Høst \& Søn.

Bock, J. Kathryn \& Richard K. Warren. 1985. Conceptual accessibility and syntactic structure in sentence formulation. Cognition 21. 47-67. DOI: https://doi.org/10.1016/0010-0277(85)90023-X

Bock, Kathryn J. 1982. Toward a cognitive psychology of syntax: Information processing contributions to sentence formulation. Psychological Review 89(1). 1-47. DOI: https://doi.org/10.1037/0033295X.89.1.1

Bock, Kathryn J. 1986. Meaning, sound, and syntax: Lexical priming in sentence production. Journal of Experimental Psychology: Learning, Memory and Cognition 124. 575-586. DOI: https://doi. org/10.1037/0278-7393.12.4.575

Bock, Kathryn J., Helga Loebell \& Randal Morey. 1992. From conceptual roles to structural relations: Bridging the syntactic cleft. Psychological Review 99(1). 150-171. DOI: https://doi. org/10.1037//0033-295X.99.1.150

Branigan, Holly P., Martin J. Pickering \& Mikihiro Tanaka. 2008. Contributions of animacy to grammatical function assignment and word order during production. Lingua 118. 172-189. DOI: https://doi.org/10.1016/j.lingua.2007.02.003

Bresnan, Joan, Anna Cueni, Tatiana Nikitina \& R. Harald Baayen. 2007. Predicting the dative alternation. In G. Boume, I. Kraemer \& J. Zwarts (eds.), Cognitive foundations of interpretation, Amsterdam: Royal Netherlands Academy of Science.

Bresnan, Joan \& Jennifer Hay. 2008. Gradient grammar: An effect of animacy on the syntax of give in New Zealand and American English. Lingua 118(2). 245-259. DOI: https://doi.org/10.1016/j. lingua.2007.02.007

Bresnan, Joan \& Marilyn Ford. 2010. Predicting syntax: Processing dative constructions in American and Australian varieties of English. Language 86(1). 186-213. DOI: https://doi.org/10.1353/lan.0.0189

Bresnan, Joan, Shipra Dingare \& Christopher D. Manning. 2001. Soft constraints mirror hard constraints: Voice and person in English and Lummi. In Miriam Butt \& Tracy Holloway King (eds.), Proceedings of the lfg01 conference. Hong Kong.

Buckle, Leone, Elena Lieven \& Anna L. Theakston. 2017. The effects of animacy and syntax on priming: A developmental study. Frontiers in Psychology 8. DOI: https://doi.org/10.3389/fpsyg.2017.02246

Cardinaletti, Anna \& Michal Starke. 1999. The typology of structural deficiency: A case study of the three classes of pronouns. In Henk van Riemsdijk (ed.), Clitics in the languages of europe 5. 145-234. Berlin, New York: De Gruyter Mouton. DOI: https://doi.org/10.1515/9783110804010.145

Comrie, Bernard. 2081. Language universals and linguistic typology. Oxford: Blackwell.

Cooper, William E. \& John R. Ross. 1975. World order. In Papers from the parasession on functionalism, 63-111. Chicago Linguistic Society.

Cresti, Emanuela \& Massimo Moneglia (eds.). 2005. C-ORAL-ROM integrated reference Corpora for spoken romance languages. Amsterdam, USA: John Benjamins. DOI: https://doi.org/10.1075/scl.15

Croft, William. 1988. Agreement vs. case marking in direct objects. In M. Barlow \& C. A. Ferguson (eds.), Agreement in natural language: approaches, theories, descriptions, 159-80. Stanford: CSLI.

da Cunha, Yanis \& Anne Abeillé. 2020. L'alternance actif/passif en français : une étude statistique sur corpus écrit. Discours 27. DOI: https://doi.org/10.4000/discours.10956 
Dalrymple, Mary \& Irina Nikolaeva. 2011. Objects and information structure. Cambridge: Cambridge University Press.

Dubois, Jean \& Françoise Dubois-Charlier. 1997. Les verbes français. Paris: Larousse-Bordas.

Faghiri, Pegah \& Juliette Thuilier. 2018. Ordre des compléments postverbaux en français : poids et accessibilité discursive. In F. Neveu, B. Harmegnies, L. Hriba \& S. Prévost (eds.), Shs web conference: 6ème congress mondial de linguistique française. DOI: https://doi.org/10.1051/shsconf/20184614008

Feleki, E. \& Holly Branigan. 1999. Conceptual accessibility and serial order in greek speech production. In M Hahn \& SC Stoness (eds.), Proceedings of the 21st annual conference of the cognitive science society, 96-101. Lawrence Erlbaum Associates.

Fenk-Oczlon, Gertraud. 1989. Word frequency and word order in freezes. Linguistics 27. 517-556. DOI: https://doi.org/10.1515/ling.1989.27.3.517

Ferreira, Fernanda. 1994. Choice of passive voice is affected by verb type and animacy. Journal of Memory and Language 33(6). 715-736. DOI: https://doi.org/10.1006/jmla.1994.1034

Galliano, Sylvain, Edouard Geoffrois, Jean-François Bonastre, Guillaume Gravier, Djamel Mostefa \& Khalid Choukri. 2006. Corpus description of the ESTER evaluation campaign for the rich transcription of French broadcast news. In Proceedings of lrec 2006, 315-320.

Gelman, Andrew \& Jennifer Hill. 2007. Data analysis using regression and multilevel/hierarchical models. Cambridge: Cambridge University Press. DOI: https://doi.org/10.1017/CBO9780511790942

Gries, Stefan Th. 2003. Towards a corpus-based identification of prototypical instances of constructions. Annual Review of Cognitive Linguistics 1. 1-27. DOI: https://doi.org/10.1075/arcl.1.02gri

Gundel, Jeannette K. 1988. Universals of topic-comment structure. In M. Hammond, E. A. Moravcsik \& J. R. Wirth (eds.), Studies in syntactic typology. John Benjamins. DOI: https://doi.org/10.1075/tsl.17.16gun

Kempen, Gerard \& Karin Harbusch. 2004. A corpus study into word order variation in German subordinate clauses: Animacy affects linearization independently of grammatical function assignment. In T. Pechmann \& C. Habel (eds.), Multidisciplinary approaches to language production, 173-181. Berlin: Mouton de Gruyter. DOI: https://doi.org/10.1515/9783110894028.173

Lazard, Gilbert. 1998. Actancy. Berlin/New York: Mouton de Gruyter. DOI: https://doi. org/10.1515/9783110808100

Lombardi, Linda \& Mary C. Potter. 1992. The regeneration of syntax in short term memory. Journal of Memory and Language 6(31). 713-733. DOI: $h$ ttps://doi.org/10.1016/0749-596X(92)90036-W

McDonald, Janet, Kathryn J. Bock \& Michael Kelly. 1993. Word and world order: Semantic, phonological and metrical determinant of serial position. Cognitive Psychology 25. 188-230. DOI: https://doi. org/10.1006/cogp.1993.1005

Morolong, Malillo \& Larry M. Hyman. 1977. Animacy, objects and clitics in Sesotho. Studies in African Linguistics 8(3). 199-218.

New, Boris. 2006. Lexique 3 : une nouvelle base de données lexicales. In Piet Mertens, Cédrick Fairon, Anne Dister \& Patrick Watrin (eds.), Actes de la conférence sur le traitement automatique des langues naturelles (taln 2006), 892-900. Louvain: Presses Universitaires de Louvain.

Potter, Mary C. \& Linda Lombardi. 1990. Regeneration in the short-term recall of sentences. Journal of Memory and Language 6(29). 633-654. DOI: https://doi.org/10.1016/0749-596X(90)90042-X

Prince, Ellen F. 1981. Toward a taxonomy of given-new information. In P. Cole (ed.), Radical pragmatics, 223-256. New York: Academic Press.

R Development Core Team. 2011. R: A language and environment for statistical Computing. Vienne, Autriche: R Foundation for Statistical Computing. http://www.R-project.org/.

Schmitt, Christian. 1987a. À propos de l'impact de la sémantique sur la séquence des compléments d'objets en français moderne. Travaux de linguistique et de littérature 25(1). 283-298.

Schmitt, Christian. 1987b. Sémantique et prédétermination de l'ordre des mots en français contemporain. Travaux de linguistique 14/15. 21-31.

Seddah, Djamé, Marie Candito, Benoît Crabbé \& Enrique Henestroza Anguiano. 2012. Ubiquitous usage of a French large corpus: Processing the Est-Republicain corpus. In Nicoletta Calzolari, Khalid Choukri, Thierry Declerck, Mehmet Uğur Doğan, Bente Maegaard, Joseph Mariani, Jan Odijk \& Stelios Piperidis (eds.), Proceedings of the 8th international conference on language resources and evaluation (lrec'12). Istanbul: European Language Resources Association (ELRA).

Tanaka, M., H. P. Branigan \& M. J. Pickering. 2011. Conceptual influences on word order and voice in sentence production: Evidence from Japanese. Journal of Memory and Language 65(3). 168-182. DOI: https://doi.org/10.1016/j.jml.2011.04.009

Thompson, Sandra A. 1990. Information flow and dative shift in English discourse. In Jerold A. Edmondson, Crawford Feagin \& Peter Mühlhäusler (eds.), Development and diversity, language variation Across space and time, 239-253. Dallas, Texas: Summer Institute of Linguistics and University of Arlington.

Thuilier, Juliette. 2012a. Contraintes préférentielles et ordre des mots en français: Université Paris 7 dissertation. 
Thuilier, Juliette. 2012b. Lemme verbal et classe sémantique dans l'ordonnancement des compléments postverbaux. In Actes du 3ème congress mondial de linguistique française 2012 (cmlf 2012). DOI: https://doi.org/10.1051/shsconf/20120100172

Thuilier, Juliette, Anne Abeillé \& Benoît Crabbé. 2014. Ordering preferences for postverbal complements in French. In Tyne, André, Benzitoun, Boulton \& Greub (eds.), French through corpora: Ecological and data-driven perspectives in French language studies, 77-102. Cambridge: Cambridge Scholars Publishing.

Thuilier, Juliette \& Laurence Danlos. 2012. Semantic annotation of French corpora: Animacy and verb semantic classes. In Proceedings of the eighth international conference on language resources and evaluation (Irec'12).

Toivonen, Ida. 2003. Non-projecting words: A case study of swedish verbal particles. Dordrecht: Kluwer. DOI: https://doi.org/10.1007/978-94-010-0053-6

Wasow, Thomas. 1997. Remarks on grammatical weight. Language Variation and Change 9. 81-105. DOI: https://doi.org/10.1017/S0954394500001800

Yamamoto, Mutsumi. 1999. Animacy and reference: A cognitive approach to corpus linguistics. John Benjamins. DOI: https://doi.org/10.1075/slcs. 46

Zaenen, Annie, Jean Carletta, Gregory Garretson, Joan Bresnan, Andrew Koontz-Garboden, Tatiana Nikitina, M. Catherine O'Connor \& Tom Wasow. 2004. Animacy encoding in English: Why and how. In Bonnie Webber \& Donna K. Byron (eds.), Proceedings of the acl 2004 workshop on discourse annotation, 118-125. Barcelona: Association for Computational Linguistics. DOI: https://doi. org/10.3115/1608938.1608954

Ziegler, Jayden, Giulia Bencini, Adele Golberg \& Jesse Snedeker. 2019. How abstract is syntax? Evidence from structural priming. Journal of Experimental Psychology: Learning, Memory and Cognition 193. 104-145. DOI: https://doi.org/10.1016/j.cognition.2019.104045
Thuilier et al.
TO CITE THIS ARTICLE: Thuilier, Juliette, Margaret Grant, Benoît Crabbé and Anne Abeillé. 2021. Word order in French: the role of animacy. Glossa: a journal of general linguistics 6(1): 55. 1-21. DOI: https://doi.org/10.5334/ gjgl.1155

Submitted: 04 November 2019 Accepted: 08 December 2020 Published: 21 April 2021

\section{COPYRIGHT:}

(c) 2021 The Author(s). This is an open-access article distributed under the terms of the Creative Commons Attribution 4.0 International License (CC-BY 4.0), which permits unrestricted use, distribution, and reproduction in any medium, provided the original author and source are credited. See http:// creativecommons.org/ licenses/by/4.0/.

Glossa: a journal of general linguistics is a peer-reviewed open access journal published by Ubiquity Press. 